\title{
Konsep Pendidikan Islam dengan Paradigma Humanis
}

\author{
H.Subaidi \\ Dosen UNISNU Jepara \\ zubaidimasyhud@yahoo.co.id
}

\begin{abstract}
:
Education is a rehumanisme, that was oriented to form individuals who able to understand the reality itself and the surrounding communities. The aim of education is to create significant social change in the life of mankind. One of the contents of the national education goals is to appreciate the reality of humanity and the potential that owned learners (human). Islam in its victorius was a center of the study of various discipline. It was proved by the emergence of Muslim scientists. But over time, the Islamic intellectualism began to decline along with cultural understanding and taqlid, whereas alQur'an have many signaled to examines all disciplines, not limited to the religious sciences. It can be seen from the verses of al-Qur'an that ordered to examine the verses kauniyah. Thus Islamic comprehensive assessment is a paradigm of Humanist Islamic Education or in other words, humanize human accordance with the primary task of man as a khalifah on earth. Keywords: Islamic Education, Paradigm, and Humanist.
\end{abstract}

\begin{abstract}
Abstrak:
Pendidikan merupakan pemanusiaan kembali manusia (humanisasi) yang berorientasi pada bentuknya individu yang mampu memahami realitas dirinya dan masyarakat sekitarnya serta bertujuan untuk menciptakan perubahan sosial secara signifikan dalam kehidupan umat manusia. Salah satu isi dari tujuan pendidikan nasional adalah menghargai realitas kemanusiaan dan berbagai potensi yang dimilki peserta didik (manusia). Islam pada masa kejayaannya menjadi pusat kajian berbagai disiplin ilmu, hal ini terbukti dengan bermunculannya para ilmuwan muslim. Tetapi seiring dengan berjalannya waktu, intelektualisme Islam itu mulai redup seiring dengan pemahaman dan budaya taqlid, padahal al-Qur`an banyak memberikan isyarat agar mengkaji semua disiplin ilmu, tidak terbatas ilmuilmu agama saja. Hal ini bisa dilihat dari ayat-ayat al-Qur'an yang memerintahkan untuk mengkaji ayat-ayat kauniyah. Dengan demikian Pengkajian Islam secara komprehenshif baik ilmu agama maupun umum adalah sebagai Paradigma Pendidikan Islam Humanis atau dengan kata lain memanusiakan manusia sesuai dengan tugas utama manusia sebagai khalifah di muka bumi.
\end{abstract}

Kata kunci: Pendidikan Islam, Paradigma, dan Humanis. 


\section{A. Pendahuluan}

Pendidikan mempunyai peran strategis sebagai sarana human resources dan human investment. Artinya, pendidikan selain bertujuan menumbuhkembangkan kehidupan yang lebih baik, juga telah ikut mewarnai dan menjadi landasan moral dan etik dalam proses pemberdayaan jati diri bangsa. ${ }^{1}$

Berangkat dari arti penting pendidikan ini, terutama pendidikan agama Islam, maka wajar jika hakekat pendidikan merupakan proses humanisasi, yang berimplikasi pada proses kependidikan dengan orientasi pengembangan aspek-aspek kemanusiaan manusia, yakni aspek fisik-biologis dan ruhaniah-psikologis. $^{2}$

Humanisasi bagi Malik Fadjar berimplikasi pada proses kependidikan dengan orientasi pengembangan aspek-aspek kemanusiaan manusia, yakni aspek fisik-biologis dan ruhaniahpsikologis. Aspek rohaniah-psikologis inilah yang dicoba didewasakan dan di-insan kamil-kan melalui pendidikan sebagai elemen yang berpretensi positif dalam pembangunan kehidupan yang berkeadaban ${ }^{3}$. Sebagaimana pernyataan Ahmad

${ }^{1}$ Karnadi Hasan, Konsep Pendidikan Jawa, dalam Jurnal Dinamika Islam dan Budaya Jawa, No 3, (Semarang : Pusat Pengkajian Islam Strategis, IAIN Walisongo, 2000). hlm. 29.

${ }^{2}$ Paulo Freire., Pendidikan: Kegelisahan Sepanjang Zaman (Pilihan Artikel Basis), Sindhunata (editor), Kanisius, sebagaimana di kutip dalam Resensi Amanat, Edisi 84/Februari 2001). hlm. 16

${ }^{3}$ Malik Fadjar dalam Imam Tholkah, Membuka Jendela Pendidikan, Jakarta: Raja Grafindo Persada., 2004) hlm. v 
Tafsir ${ }^{4}$ bahwa pendidikan itu harus mampu mendidik manusia menjadi manusia.

Seseorang dapat dikatakan telah menjadi manusia bila telah memiliki nilai (sifat) kemanusiaan. Karena itu tujuan mendidik ialah me-manusia-kan manusia. Dalam bagian lain, Paulo Freire $^{5}$ juga mengatakan bahwa hakekat dari pendidikan adalah pembebasan, yang merupakan pengukuhan manusia sebagai subyek yang terarah kepada obyek, menghasilakan pengetahuan, yang diekspresikan melalui bahasa.

Banyak pihak mengatakan bahwa, telah terjadi "dehumanisasi” pendidikan, dengan indikasi terkikisnya nilainilai kemanusiaan yang dikandungnya. Bahkan pendidikan mengalami "kegagalan", hal ini terlihat dari beberapa kasus dan akibat dari perbuatan buruk orang-orang yang lepas dari kontrol ajaran agama yang belakangan banyak muncul ke permukaan, seperti, nilai-nilai kehidupan umat manusia lebih banyak didasarkan pada nilai kegunaan, kelimpahan hidup materealistik, sekularistik dan hedonistik yang menafikan aspek etika-relegius, moralitas dan humanistik. ${ }^{6}$

Ini semua mengindikasikan bahwa pendidikan belum mempunyai peran yang signifikan dalam proses

4 Ahmad Tafsir, Metodologi Pengajaran Agama Islam, (Bandung: Remaja Rosdakarya. 1995). hlm. 46

5 Paulo Freire, Politik Pendidikan: Kebudayaan, Kekuasaan, dan Pembebasan, terj. Agung Prihantoro dan Fuad Arif Fudiyartanto, (Yogyakarta: Pustaka Pelajar \& READ Paulo Freire 1984). hlm. 43

6 Arifin, HM, Kapita Selekta Pendidikan (Islam\&Umum), (Jakarta: Aksara. 1991) hlm. 57 
membangun kepribadian anak bangsa yang mempunyai jiwa sosial dan kemanusiaan.

Dari pemikiran diatas, penulisan ini diharapkan mampu mengeksplorasi universalitas ajaran Islam dalam teks al Qurán tentang humanisme dan implikasinya dalam pendidikan Islam sebagai kerangka paradigmatik.

\section{B. PENDIDIKAN ISLAM}

Dalam Kamus Besar Bahasa Indonesia, pendidikan berasal dari kata dasar didik (mendidik), yaitu memelihara dan memberi latihan (ajaran, pimpinan) mengenai akhlak dan kecerdasan pikiran. $^{7}$

Joe Park merumuskan pendidikan sebagai the art or process of imparting or acquiring knowledge and habit through instructional as strudy. Di dalam definisi ini tekanan kegiatan pendidikan diletakkan pada pengajaran (instruction). Sedangkan segi kepribadian yang dibina adalah aspek kognitif dan kebiasaan.

Ki Hajar Dewantara mengartikan pendidikan sebagai daya upaya untuk memajukan budi pekerti, pikiran serta jasmani anak, agar dapat memajukan kesempurnaan hidup yaitu hidup dan menghidupkan anak yang selaras dengan alam dan masyarakatnya.

Pendidikan adalah bimbingan secara sadar oleh pendidik kepada terdidik terhadap perkembangan jasmani dan rohani si

${ }^{7}$ Dep. P dan K, Kamus Besar Bahasa Indonesia, (Jakarta: Balai Pustaka.1994), hlm. 232 
terdidik menuju kepribadian yang lebih baik, yang pada hakikatnya mengarah pada pembentukan manusia yang ideal ${ }^{8}$

Manusia ideal adalah manusia yang sempurna akhlaknya. Yang nampak dan sejalan dengan misi kerasulan Nabi Muhammad saw., yaitu menyempurnakan akhlak yang mulia. Agama Islam adalah agama universal yang mengajarkan kepada umat manusia mengenai berbagai aspek kehidupan baik kehidupan yang sifatnya duniawi maupun yang sifatnya ukhrawi.

Dari etimologi dan analisis pengertian pendidikan di atas, secara singkat pendidikan dapat dirumuskan sebagai tuntunan pertumbuhan manusia sejak lahir hingga tercapai kedewasaan jasmani dan rohani, dalam interaksi dengan alam dan lingkungan masyarakatnya.

Adapun pendidikan Islam memiliki beberapa karakteristik yang berbeda dengan pengertian pendidikan secara umum. Beberapa pakar pendidikan Islam memberikan rumusan pendidikan Islam, diantaranya Yusuf Qardhawi, mengatakan pendidikan Islam adalah pendidikan manusia seutuhnya, akal dan hatinya, rohani dan jasmaninya, akhlak dan ketrampilannya. Karena pendidikan Islam menyiapkan manusia untuk hidup, baik dalam keadaan aman maupun perang, dan menyiapkan untuk menghadapi masyarakat dengan segala kebaikan dan

${ }^{8}$ Abudin Nata, Filsafat Pendidikan Islam, (Jakarta: Logos, cet. Ke42001), hlm. 101 . 
kejahatannya, manis dan pahitnya. ${ }^{9}$ Omar Mohammad atToumy as-Syaibany ${ }^{10}$ mengatakan bahwa ia sebagai proses pengubahan tingkah laku individu pada kehidupan pribadinya atau masyarakat serta alam sekitar melalui proses pengajaran sebagai suatu aktivitas asasi dan proporsi di antara profesiprofesi asasi dalam masyarakat.

Zakiah Darajat ${ }^{11}$ mengatakan bahwa pendidikan Islam sebagai pendidikan individu dan masyarakat yang berisikan ajaran tentang sikap dan tingkah laku terbentuk pribadi menuju kesejahteraan hidup.

Dr. Muhammad SA Ibrahimy (Bangladesh) mengemukakan pengertian pendidikan Islam sebagi berikut: Islamic education in true sense of the term, is a system of education which enables a man to lead his life according to the islamic ideology, so that he may easily mould his life in according with tenent of islam. Bisa dipahami bahwa "pendidikan dalam pandangan yang sebenarnya adalah suatu sistem pendidikan yang memungkinkan seseorang dapat mengarahkan kehidupannya sesuai dengan cita-cita Islam, sehingga dengan mudah ia dapat membentuk hidupnya sesuai dengan ajaran Islam".

${ }^{9}$ Yusuf al-Qardhawi, Tarbiyah al-Islamiyah wa Madrasah Hasan alBanna, diterjemahkan oleh Bustani A. Gani, Pendidikan Islam dan Madrasah Hasan al-Banna, (Jakarta: Bulan Bintang 1980), hlm. 39.

10 Omar Mohammad at-Toumy as-Syaibany Falsafah Pendidikan Islam, (Jakarta:Bulan Bintang, 1979), hlm. 399.

11 Zakiah Darajat, Ilmu Pendidikan Islam, Jakarta: Bumi Aksara, Cet.7, 2008), hlm. 28 
Terkait dengan konteks ini, Muhammad Fadhil al-Jamali ${ }^{12}$ menyatakan bahwa pendidikan Islam adalah upaya mengembangkan, mendorong serta mengajak manusia untuk lebih maju dengan berlandaskan nilai-nilai yang tinggi dan kehidupan yang mulia, sehingga terbentuk pribadi yang lebih sempurna berkaitan dengan akal, perasaan, maupun perbuatan.

Terkait dengan definisi tersebut diatas, lahirlah tiga prinsip pendidikan Islam sebagai berikut:

1. Pendidikan merupakan proses perbantuan pencapaian tingkat keimanan dan berilmu.

2. Sebagai model, maka Rasulullah saw. sebagai uswatun hasanah $^{13}$ yang dijamin oleh Allah SWT. memiliki akhlak mulia (al-akhlak al-karîmah) ${ }^{14}$

3. Pada diri seorang manusia terdapat potensi baik dan buruk $^{15}$ potensi negatif seperti lemah. ${ }^{16}$

Dari uraian di atas, dapat dilihat perbedaan-perbedaan antara pendidikan secara umum dengan pendidikan Islam. Perbedaan utama yang paling menonjol adalah bahwa pendidikan Islam bukan hanya mementingkan pembentukan pribadi untuk kebahagiaan dunia, tetapi juga untuk kebahagiaan

12 dalam Abdul Mujib, Ilmu Pendidikan Islam, (Jakarta: Kencana, Cet.2. 2008), hlm. 26

${ }^{13}$ QS. Al-Ahzab (33) :21

${ }^{14}$ QS. Al-Qalam (68):4.

${ }^{15}$ QS. Asy-Syam (91):7-8

${ }^{16}$ QS. An-Nisa' (4) : 28; Bukhari Umar, Ilmu Pendidikan Islam.t.t). hlm. 26. 
akhirat. Selain itu pendidikan Islam berusaha membentuk pribadi yang bernafaskan ajaran-ajaran Islam. ${ }^{17}$

\section{Humanisme}

Kata "humanis" dalam kamus ilmiah popular berarti, suatu doktrin yang menekankan pada kepentingan-kepentingan manusia dan ideal Humanis sebagai aliran filsafat modern yang "anti-religius", Tetapi dalam pengertian yang lain, dimana para pendukungnya begitu optimistik tentang kemungkinankemungkinan atau kemampuan manusia. Filsafat humanisme mempunyai beberapa pandangan hidup yang berpusat pada kebutuhan dan ketertarikan manusia. ${ }^{18}$

Makna kemanusiaan harus selalu dirumuskan secara baru dalam setiap perjumpaan dengan realitas dan konteks yang baru. Kemanusiaan perlu dilihat bukan sebagai esensi tetap atau situasi akhir. Makna kemanusiaan adalah proses menjadi manusiawi dalam interaksi antar manusia dengan konteks dan tantangan yang terus berkembang. ${ }^{19}$ Menurutnya, dalam situasi pluralisasi kehidupan dan kebudayaan sekarang, tidak mungkin dirumuskan satu corak humanisme.

Satu hal yang tak bisa ditiadakan dalam humanisme ialah harkat dan martabat manusia harus dihormati dan dikembangkan. Dalam hal ini filsafat berfungsi menafsirkan

17 Azyumardi Azra, Esei-esei Intelektual Muslim Pendidikan Islam, (Ciputat: Logos 1999). hlm. 6.

18 Abdurrahman Mas'ud, Menggagas Pendidikan Nondikotomik, (Yogyakarta: Gama Media.2002). hlm. 129

19 Michael Sastrapratedja SJ dalam pidato pengukuhan guru besar ilmu filsafatnya di Aula STF Driyarkara, (Jakarta: Sabtu 8 Maret 2006. 
pengalaman manusia dan berbagai tradisi budaya. Dari sana tercipta pemahaman antara budaya yang pada gilirannya akan memberikan kontribusi bagi peningkatan hidup dan martabat manusia.

Penerapan teori humanis dalam ranah pendidikan, sebagaimana pandangan Gage dan Berliner terdapat beberapa prinsip dasar dari pendekatan humanistik yang bisa diterapakan untuk mengembangkan pendidikan:

1. Peserta didik akan belajar dengan baik terhadap apa yang ia inginkan dan perlu ia ketahui. Saat ia telah mengembangkan kemampuan untuk menganalisa apa dan mengapa sesuatu penting untuk nya, sesuai dengan kemampuan yang ada, kemudian untuk mengarahkan perilakunya untuk mencapai hal-hal yang diinginkan. Peserta didik akan belajar dengan lebih mudah dan cepat. Sebagian besar pendidik dan ahli teori belajar akan setuju dengan dengan pernyataan ini, meskipun mereka mungkin akan tidak setuju tentang apa tepatnya yang menjadi motivasi peserta didik tersebut.

2. Mengetahui bagaimana cara belajar, ini lebih penting dari pada membutuhkan banyak pengetahuan. Dalam dunia sosial dewasa ini, keberadaan ilmu pengetahuan dan teknologi berkembang dan berganti dengan begitu sangat cepat, pandangan ini banyak dirasakan diantara kalangan pendidik atau guru, terutama datang dari sudut pandang kognitif.

3. Evaluasi diri, ini adalah satu satunya evaluasi untuk pekerjaan bagi peserta didik. Penekanannya adalah fokus kepada perkembangan internal dan regulasi diri. Terkait 
dengan konteks ini, banyak tenaga pengajar yang sepakat bahwa model evaluasi ini adalah hal yang penting, mereka juga akan mengawal bahwa ini adalah sebuah kebutuhan untuk mengembangkan kemampuan peserta didik untuk mengahdapi dunia eksternal. Pertemuan dengan pengaharapan eksternal seperti ini menghadapkan pertentangan pada sebagian besar teori humanistik.

4. Perasaan, ia adalah sama penting dengan kenyataan. Banyak tugas dari pandangan humanistik seakan memvalidasi poin ini dan dalam satu area, pendidik yang berorientasi humanistik membuat sumbangan yang berarti untuk dasar pengetahuan yang ada.

5. Murid akan belajar dengan lebih baik dalam lingkungan yang tidak mengancam. Ini adalah salah satu area dimana seorang pendidik humanistik telah memiliki dampak dalam praktek pendidikan. Orientasi yang mendukung saat ini adalah lingkungan harus tidak mengancam baik secara psikologis, emosional dan fisik.

\section{Humanis Dalam Islam}

Islam merupakan agama yang menjadikan manusia sebagaimana adanya, atau lebih tepatnya, Islam selaras dengan fitrah manusia. Sebagaimana diterangkan dalam QS. Ar-Rum: 30:

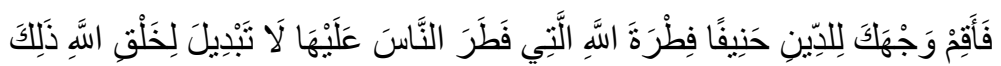

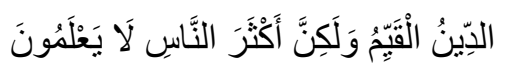


"Maka hadapkanlah wajahmu dengan lurus kepada agama agama (Allah), tetaplah atas fitrah Allah (agama) yang telah menciptakan manusia menurut fitrahnya itu, tidak ada perubahan pada fitrah Allah. (itulah) Agama yang lurus, tetapi kebanyakan manusia tidak mengetahuinya".

Dari ayat di atas, terjalin suatu pengertian, bahwa fitrah manusia pada dasarnya selaras dengan fitrah (agama) Allah. Demikian juga sebaliknya, agama Islam sebagai fitrah Allah yang selaras dengan fitrah manusia. Adapun fitrah yang dimaksud ini, mengacu pada fitrah manusia bermakna keadaan asli alami yang dibawa manusia ketika lahir. Dengan berdasarkan pada pengertian tersebut, akan dibahas terkait dengan manusia menurut pandangan Islam yang akan menjadi dasar pijakan bagi sebuah pendidikan Islam yang humanis, yang meliputi hakikat wujud manusia, potensi insaniyah manusia, dan tujuan penciptaan manusia.

Hakikat pendidikan humanis menurut Abdul Munir Mulkhan mencakup tiga entitas, yaitu; 1) Pendidikan sebagai proses peneguhan keunikan manusia. Maksudnya, kesadaran keunikan diri sebagai pengalaman otentik perlu ditempatkan sebagai akar pendidikan, pengembangan politik kebangsaan, dan kesalehan religius. Keunikan adalah basis pribadi . kreatif dan kecerdasan setiap orang dengan kemampuan dan sikap hidup berbeda. 2) Pendidikan sebagai proses akumulasi pengalaman manusia. Maksudnya, proses pendidikan perlu ditempatkan sebagai media pengayaan (akumulasi) pengalaman. 3) Pendidikan sebagai proses penyadaran. Hakikat pendidikan menurut Mulkhan tidak lain 
sebagai proses penyadaran diri dari realitas universum. Penyadaran bukan awal sebuah dinamika kehidupan melainkan akar dari seluruh. dinamika kehidupan yang terus aktual dan terpelihara. Sementara itu, aplikasi konsep pendidikan humanis Abdul Munir Mulkhan dalam pendidikan agama Islam menyentuh wilayah tujuan, kurikulum, evaluasi, metode, pendidik dan peserta didik. ${ }^{20}$

Pembentukan nilai-nilai manusia yang selaras dengan tujuan penciptaannya sangat diperlukan. Sebagaimana kehendak Allah SWT. menjadikan manusia sebagai khalifah di muka bumi. Selain dari tujuan penciptaan manusia untuk tunduk dan patuh kepada Allah, tujuan lain yang tidak kalah pentingnya adalah sebagai wakil Allah dimuka bumi (Khalifatullah Fil Ard). Hal ini secara jelas di tegaskan di dalam Al-Quran:

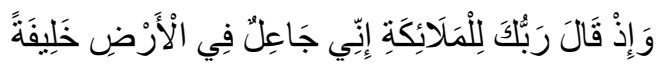

Artinya:"Ingatlah ketika Tuhanmu berfirman kepada malaikat: "Sesungguhnya Aku hendak menjadikan seorang kholifah dimuka bumi." 21

Keberanian moral peserta didik merupakan dorongan dari iman dan akhlak yang berakar pada wahyu Tuhan, sehingga manusia selalu melancarkan “ 'amr al-ma'ruf nahyi 'an almunkar", sebagi bentuk kreatifitas manusia baik ia sebagai 'abdullah maupun khalifatullah yang mana di dalamnya

${ }^{20}$ Lihat makalah Dr.H.Ihsan, Seminar dan Lokakarya "Tawuran Pelajar: Problem Tradisi, karakter, atau Kurikulum?”, 20 Oktober 2012 di Hotel Griptha Kudus.

${ }^{21}$ Q.S. Al-Baqarah: 30). 
tercermin kehidupan yang mandiri, terbebaskan dari rasa takut demi kesejahteraan, keadilan dan perwujudan kemanusiaan.

Dalam hal ini Allah berfirman dalam QS. Ali Imran: 104:

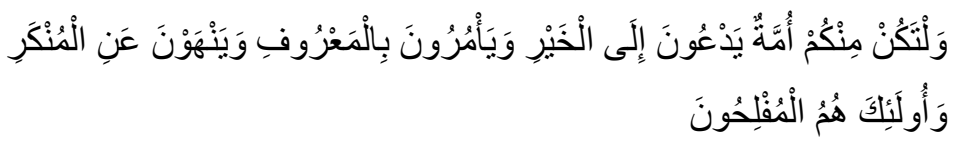

"Dan hendaklah ada di antara kamu segolongan umat yang menyeru kepada kebajikan, menyuruh kepada yang makruf dan mencegah dari yang munkar; merekalah orangorang yang beruntung”.

Kebebasan dalam pandangan pendidikan Islam yang perlu digaris bawahi adalah masih adanya keterikatan dengan normanorma dan pesan-pesan Ilâhiyah baik yang terangkum dalam alQur'an maupun as-Sunnah. Jadi, yang dimaksud dengan humanisasi pendidikan Islam dalam karya ilmiah ini adalah penerapan konsep humanisme dalam pendidikan Islam secara riil sebagaimana dicontohkan oleh Nabi Muhammad saw. dan digambarkan oleh Allah SWT. melalui firman-Nya dalam QS. Ali Imran: 159:

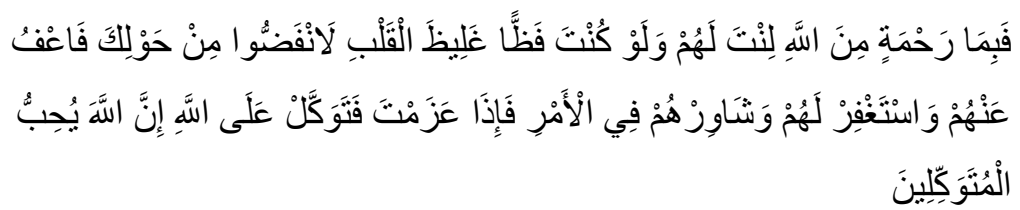

"Maka disebabkan rahmat Allahlah kamu berlaku lemah lembut terhadap mereka. Sekiranya kamu bersikap keras lagi kasar, tentulah mereka menjauhkan diri dari sekelilingmu. Karena itu maafkanlah mereka dalam urusan itu. Kemudian apabila kamu telah membulatkan tekad, bertakwalah kepada 
Allah. Sesungguhnya Allah menyukai orang-orang yang bertawakal kepada-Nya."

Humanisme yang dimaksud dalam Islam adalah memanusiakan manusia sesuai dengan perannya sebagai khalifah di bumi ini.

Menurut KH. HMA. Sahal Mahfudh, Islam memandang dan meletakkan manusia dalam dua aspek dasar peran dan fungsi, yaitu 'ibadah dan 'imarah al-ardl (pengelolaan bumi), kedua aspek dasar ini adalah bagian yang tidak dapat dipisahka, dua sisi keping yang sama dari kedudukan manusia sebagai khalifah Allah di bumi. Fungsi 'ibadah, meletakkan manusia dalam posisi hamba Tuhan sepenuhnya, sementara fungsi 'imarah al-ardl justru memberi kuasa penuh kepada manusia untuk mengelola kehidupannya. ${ }^{22}$

\section{E. Paradigma Pendidikan Islam Humanis Prespektif Al- Qur`An}

Paradigma merupakan istilah yang dipopulerkan Thomas Khun dalam karyanya The Structure of Scientific Revolution.$^{23}$. Paradigma di sini diartikan Khun sebagai kerangka referensi atau pandangan dunia yang menjadi dasar keyakinan atau pijakan suatu teori. Pemikir lain seperti Patton sebagaimana dikutip Mansour Fakih mendefinisikan pengertian paradigma

${ }^{22}$ Terinspirasi dari makalah KH.Sahal Mahfudh, Seminar Sehari SMU Islam Sudirman, (Semarang: Desember 1999), hlm. 6.

23 Thomas Khun, The Stucture of Scientific Revolutions; Peran Paradigma Dalam Revolusi Sains, (trj), (Bandung: Rosdakarya 1970). hlm. 134 
hampir sama dengan Khun yaitu sebagai "a world view, a general perspective, a way of breaking down of the compexity of the real world", (suatu pandangan dunia, suatu cara pandang umum atau suatu cara untuk menguraikan kompleksitas dunia nyata). ${ }^{24}$ Sementara itu Syaikh Taqiyuddin al-Nabhani menggunakan istilah lain yang maknanya hampir sama dengan paradigma yaitu al-qa`idah fikriyah yang berarti pemikiran dasar yang menjadi landasan bagi pemikiran-pemikiran lainnya. $^{25}$

Dalam bagian lain pendidikan memerlukan pengembangan yang memiliki proyeksi kemanusiaan, karena pada akhirnya siswa (manusia) harus mempertangungjawabkan segala tindakan dan perbuatannya dalam kehidupan sosialnya. Kekurang cermatan kebijakan pendidikan dalam memahami siswa sebagai manusia yang unik dan mandiri serta harus secara pribadi mempertangungjawabkan tindakannya, pendidikan akan berubah menjadi pemasungan daya kreatif siswa (manusia).

Di dalam pendidikan kemandirian siswa (manusia) masih lemah mengakibatkan minimnya tangung jawab yang melekat dalam pribadinya. Kenyataan ini berakar pada pandangan masyarakat dalam keragamaannya. Yaitu konsep khalifatullah masih kurang diperhatikan di banding dengan konsep 'abdullah. Secara umum, komunitas muslim berpandangan bahwa menjadi muslim yang baik, saleh, santri, adalah menjadi 'abdullah,

${ }^{24}$ Mansour Fakih, Sesat Pikir Teori Pembangunan dan Globalisasi, (Yogyakarta: Pustaka Pelajar 2001). hlm. 78

${ }^{25}$ Syaikh Taqiyuddin al-Nabhani, An-Nidzam Al-Iqtishadi fi al-Islam, Beirut: Dar al-Ummah 1990). hlm. 109. 
yakni hamba yang hanya mengabdi kepada Allah SWT. semata, dalam rangka mencari rida-Nya. Pandangan ini bukannya salah menurut agama, melainkan belum sempurna. Konsep pendidikan Islam dengan paradigma humanistik dihasilkan dari upaya refleksi dan konstruksi sejarah Islam, khususnya pada masa lima abad pertama, serta nilai-nilai normatif Islam dan dari tren humanisme universal. Ciri-ciri ini berada dalam tataran approach yang bersifat aksiomatik (kebenaran yang tidak diragukan lagi kebenarannya) dan penawaran basic principle. ${ }^{26}$

Semangat penalaran dalam intelektualisme Islam masa lalu kini telah digantikan dengan tradisi mengekor (taqlid) ${ }^{27}$ Bukti dari fenomena ini adalah jarangnya penemuan-penemuan baru selama kurun ini dari lintas disiplin keilmuan, meski banyak pemikir-pemikir yang lahir, paling banter karya yang muncul adalah karya lanjutan tokoh-tokoh terdahulu, tidak ada yang benar-benar baru. Hal ini diperparah dengan peta politik dunia yang dimotori Barat yang berideologi sekuler melalui institusiinstitusi modern yang masuk ke dunia Islam. ${ }^{28}$ Sebab internal inilah yang membuat Abdul Hamid Abu Sulaiman dalam Jurnal 'Islamization of Knowledge with special Reference of Political Science' , ${ }^{29}$ berkomentar bahwa krisis multidimensi yang

${ }^{26}$ Mujib, Pendidikan Humanis dalam Islam, (Skripsi, STAIN Salatiga 2011). hlm. 40

${ }^{27}$ Mustafa Umar dan Ziauddin Sardar, Islamisasi Peradaban, dalam A Khudhori Sholeh, Pemikiran Islam Kontemporer, (Yogyakarta: Jendela.2003). hlm. 406

${ }^{28}$ C.A. Qadir, Filsafat dan Ilmu Pengetahuan Dalam Islam, (Jakarta: Yayasan Obor Indonesia 1991) hlm. 5

29 Abdul Hamid Abu Sulaiman dalam Jurnal 'Islamization of Knowledge with special Reference of Political Science’ (1985), 
dialami umat Islam karena disebabkan beberapa hal antara lain: kemunduran umat, stagnasi pemikiran umat, absennya ijtihad umat, absennya kemajuan kultural umat.

Tujuan akhir pendidikan dalam Islam adalah proses pembentukan diri peserta didik (manusia) agar sesuai dengan fitrah keberadaannya. Terkait dengan konteks ini, mengharuskan kebebasan gerak dan langkah bagi setiap elemen dalam dunia pendidikan, terutama bagi peserta didik untuk mengembangkan potensi yang dimiliki secara maksimal. Pada masa kejayaan Islam, pendidikan telah mampu menjalankan perannya sebagai wadah pemberdayaan peserta didik, namun seiring dengan kemunduran dunia Islam, dunia pendidikan Islam pun turut mengalami kemunduran. Bahkan dalam paradigma pun terjadi pergeseran dari paradigma aktif-progresif menjadi pasif-defensif. Akibatnya, pendidikan Islam mengalami proses "isolasi diri" dan termarginalkan dari lingkungan di mana ia berada.

Dari gambaran masa kejayaan dunia pendidikan Islam di atas, terdapat beberapa hal yang dapat digunakan sebagai upaya untuk kembali membangkitkan dan menempatkan dunia pendidikan Islam pada peran yang semestinya yakni memanusiakan manusia atau humanisasi sekaligus menata ulang paradigma pendidikan Islam sehingga kembali bersifat aktif-progresif, yakni :

Pertama, menempatkan kembali seluruh aktifitas pendidikan (talab al-ilm) di bawah frame work agama. Artinya, seluruh aktifitas intelektual senantiasa dilandasi oleh nilai-nilai 
agama Islam, di mana tujuan akhir dari seluruh aktifitas tersebut adalah upaya menegakkan agama dan mencari ridla Allah SWT.,sebagaimana firman Allah SWT:

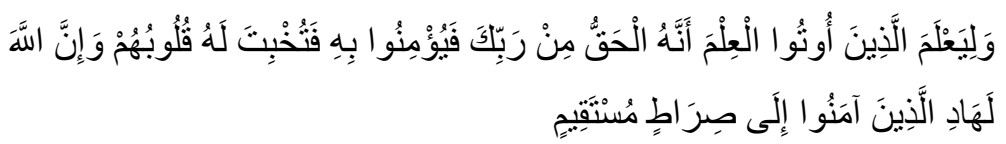

Artinya: Dan agar orang-orang yang telah diberi ilmu, meyakini bahwasanya al-Qur`an itulah yang hak dari Tuhanmu lalu mereka beriman dan tunduk hati mereka kepada-Nya dan sesungguhnya Allah adalah Pemberi Petunjuk bagi orangorang yang beriman kepada jalan yang lurus. ${ }^{30}$

Kedua, adanya perimbangan antara disiplin ilmu agama dan pengembangan intelektualitas dalam kurikulum pendidikan. Salah satu faktor utama dari marginalisasi dalam dunia pendidikan Islam adalah kecenderungan untuk lebih menitik beratkan pada kajian agama dan tidak memberikan porsi yang berimbang pada pengembangan ilmu non-agama, bahkan menolak kajian-kajian non-agama.

Oleh karena itu, penyeimbangan antara materi-materi agama dan non-agama dalam dunia pendidikan Islam adalah sebuah keniscayaan, jika ingin dunia pendidikan Islam kembali survive di tengah masyarakat. Al-Qur`an telah banyak menjelaskan dalam ayat-ayat kauniahnya, agar manusia memikirkan dan mengkaji secara mendalam terkait dengan adanya alam semesta, bagaimana keberadaan langit ditinggikan, keberadaan bumi dihamparkan, keberadaan gunung-gunung ditegakkan, manusia diciptakan dan lain sebagainya. Terkait

${ }^{30}$ QS. Al-Hajj, (22) : 54 
dengan pemahaman ayat yang merupakan pedoman dasar, mengindikasikan agar umat Islam mempelajari berbagai disiplin ilmu pengetahuan, tidak dibatasi hanya mempelajari ilmu-ilmu agama. Dan Nabi Muhammad saw. pun memerintahkan para sahabat untuk menuntut ilmu ke negeri China. Ini merupakan dasar perintah dari Nabi saw. agar umat Islam mempelajari berbagai disiplin ilmu pengetahuan baik agama maupun umum, karena China dikenal pada saat itu tercatat sebagai negeri yang memiliki berbagai ahli pengobatan atau tabib.

Menurut Mastuhu, paradigma pendidikan Islam tidak ada dikotomi antara ilmu dan agama, ilmu tidak bebas nilai, tetapi bebas dinilai, mengajarkan agama dengan bahasa ilmu pengetahuan dan tidak hanya mengajarkan sisi tradisional, melainkan sisi rasional. ${ }^{31}$

Ketiga, perlu diberikan kebebasan kepada dunia akademik, untuk melakukan pengembangan ilmu dan teknologi secara maksimal karena selama masa kemunduran Islam, tercipta banyak sekat dan wilayah terlarang bagi perdebatan dan perbedaan pendapat yang mengakibatkan sempitnya wilayah pengembangan intelektual, karena dengan model pengembangan intelektual semacam ini, akan membuka peluang lebih lebar bagi pengembangan ilmu dan teknologi di dunia pendidikan Islam secara khusus dan dunia Islam secara umum.

Keempat, mulai mencoba melaksanakan strategi pendidikan yang integrative. Artinya, strategi yang dilaksanakan sesuai

31 Mastuhu, Memberdayakan Sistem Pendidikan Islam, (Jakarta: Logos, cet. Ke-2. 1999). 15 
dengan situasi dan kondisi lingkungan di mana proses pendidikan tersebut dilaksanakan. Selain itu, materi-materi yang diberikan juga disesuaikan dengan situasi dan kondisi yang ada, setidaknya selalu ada materi yang applicable dan memiliki relasi dengan kenyataan yang ada. Dengan strategi ini diharapkan pendidikan Islam akan mampu menghasilkan sumber daya yang benar-benar mampu menghadapi tantangan zaman dan peka terhadap lingkungan.

Faktor lain yang akan sangat membantu adalah adanya perhatian dan dukungan para pemimpin (pemerintah) atas proses penggalian dan pembangkitan dunia pendidikan Islam. Adanya perhatian dan dukungan pemerintah akan mampu mempercepat penemuan kembali paradigma pendidikan Islam yang aktif-progresif. Dari sinilah, diharapkan dunia pendidikan Islam dapat kembali mampu menjalankan fungsinya sebagai sarana pemberdayaan dan humanisasi.

Dengan demikian, sikap yang harus dikembangkan dalam penyelenggaraan pendidikan Islam bukanlah "monopoli" kebenaran seorang pendidik atau guru, akan tetapi sebaliknya yaitu sikap keterbukaan serta saling menghormati dan menghargai, baik antar pesrta didik/murid maupun peserta didik dengan pendidik/guru. Humanisasi pendidikan merupakan reaksi penolakan terhadap apa yang disebut Freire dengan "pendidikan gaya bank (banking system) yang cenderung membendung inisiatif, kreativitas dan inovasi." 32

${ }^{32}$ Bambang Sarwoko, Konsep Dasar Pendidikan Luar Sekolah, cet. I, (Semarang, IKIP Semarang Press 1998). hlm. : 23 


\section{F. Penutup}

Konsep manusia, menurut pandangan Islam, dalam konteks ini, akan menjadi dasar pijakan bagi sebuah pendidikan Islam yang humanis, yang tentunya meliputi: hakikat wujud manusia, potensi insaniyah manusia, dan tujuan penciptaan manusia. Humanisasi yang diterapkan dalam al-Qur`an tidak meninggalkan peran manusia di bumi sebagaimana fungsi dan perannya sebagai 'imarah al-ardl, dan sebagai hamba yang diwajibkan untuk mengabdi kepada Sang khalik sebagaimana fungsi dan perannya sebagai 'ibad.

Adapun pendidikan Islam dengan paradigm humanis yang terdapat didalam al-Qur`an adalah: Pertama, menempatkan kembali seluruh aktifitas pendidikan (talab al-ilm) di bawah frame work agama yang bertujuan mencari ridha Allah. Kedua, adanya perbandingan antara pengetahuan agama dan pengetahuan umum. Ketiga, kebebasan dalam mengembangkan ilmu pengetahuan. Keempat, mengkaji ilmu pengetahuan yang membumi sehingga dapat diimplementasikan dalam kehidupan sehari-hari dan mulai mencoba melaksanakan strategi pendidikan yang integrative. Dari ilustrasi yang demikian ini, akan memberikan paradigma pendidikan Islam yang sejalan dengan paradigma agama. 


\section{Daftar Pustaka}

Abdul Mujib, et al. 2008, Ilmu Pendidikan Islam, Jakarta: Kencana, Cet.2.

Abdurrahman Mas'ud, 2002, Menggagas Pendidikan Nondikotomik, Yogyakarta: Gama Media.

Abuddin Nata, 2001, Filsafat Pendidikan Islam, Jakarta: Logos, 2001. cet. Ke-4.

Achmadi, 1992, Islam paradigma Ilmu Pendidikan, Yogyakarta: Aditya Media.

Ahmad Tafsir, 1995, Metodologi Pengajaran Agama Islam, Bandung: Remaja Rosdakarya.

Al-Ghazali, 1969, Ihya Ulumuddin, Kairo.

Amir an-Najar, 2004, Psikoterapi Sufistik dalam Kehidupan Modern, terj., Jakarta: Hikmah.

Arifin, HM, 1991, Kapita Selekta Pendidikan (Islam\&Umum), Jakarta: Aksara.

Azyumardi Azra, 1999, Esei-esei Intelektual Muslim Pendidikan Islam, Ciputat: Logos.

Bambang Sarwoko, 1989, Konsep Dasar Pendidikan Luar Sekolah, cet. I, Semarang, IKIP Semarang Press.

Bukhari Umar, t.t., Ilmu Pendidikan Islam.

C.A. Qadir, 1991, Filsafat dan Ilmu Pengetahuan Dalam Islam, Jakarta: Yayasan Obor Indonesia.

Corliss Lamont, 1977, The Philosophy of Humanism.

Departemen Agama RI, 1989, Al-Qur'an dan Terjemahnya, Semarang: CV. Al-Waah.

Departemen Pendidikan dan Kebudayaan, 1994, Kamus Besar Bahasa Indonesia, Jakarta: Balai Pustaka.

Dikutip dari webside Pendidikan Network, judul Artikel Melacak Paradigma Pendidikan Islam, Selasa 28 November 2006, jam 11.30.

Dikutip dari www.jjnet.com/archives/documents/humanist.htm, Senin, 27 November 2006 jam 10.00.

Encarta, 1999, World English Dictionary, Microsoft Corporation Developed for Microsoft by Bloomsbury Publishing.

Endang Saifuddin Anshari, 1976, Pokok-pokok Pikiran tentang Islam, Jakarta: Usaha Interprises.

Faisal Ismail, 2003, Masa Depan Pendidikan Islam, Jakarta: Bakti Aksara Persada. 
Fazlurrahman, 1979, Islam, Chicago : Chicago University Press.

George R. Knight, 1982, Issues and Alternatives in Educational Philosophy, Michigan: Andews University Press.

H.A.R.Gibb, 1953, Muhammadanism, A History Survey, Oxford: University Press.

Hasan Langgulung, 19980, Beberapa Pemikiran tentang Pendidikan Islam, Bandung: al-Ma`arif.

Irsjad Djuwaeli, 1998, Pembaruan Kembali Pendidikan Islam, Jakarta, Karsa Utama Mandiri dan PB Mathla'ul Anwar.

Karnadi Hasan, 2000, Konsep Pendidikan Jawa, dalam Jurnal Dinamika Islam dan Budaya Jawa, No 3, Pusat Pengkajian Islam Strategis, IAIN Walisongo Semarang.

Malik Fadjar dalam Imam Tholkah, 2004, Membuka Jendela Pendidikan, Jakarta: Raja Grafindo Persada.

Mastuhu, 1999, Memberdayakan Sistem Pendidikan Islam, Jakarta: Logos, cet. Ke-2.

Mangunwijaya, 2001,"Mencari Visi Dasar Pendidikan", Sindhunata (ed.), Pendidikan: Kegelisahan Sepanjang Zaman, Yogyakarta: Kanisius.

Mansour Fakih, 2001, Sesat Pikir Teori Pembangunan dan Globalisasi, Yogyakarta: Pustaka Pelajar.

Michael Sastrapratedja SJ, dalam pidato pengukuhan guru besar ilmu filsafatnya di Aula STF Driyarkara, Jakarta: Sabtu 8 Maret 2006.

Muhammad Fuad Abd al-Baqi, 1997 M/1418H, al-Mu jam alMufahras li Alfadz al-Qur'an, Beirut : Dar al-Fikr.

Mujib, 2011, Pendidikan Humanis dalam Islam, Skripsi, STAIN Salatiga.

Muslim Kadir, 1992, Dasar-Dasar Praktikum keberagamaan dalam Islam, Yogyakarta, Pustaka Pelajar.

Mustafa Umar, Ziauddin Sardar: Islamisasi Peradaban, dalam A Khudhori Sholeh, 2003, Pemikiran Islam Kontemporer, Yogyakarta: Jendela.

Nashori, H. Fuad. 2003. Potensi-Potensi Manusia (Seri Psikologi Islam). Yogyakarta: Pustaka Pelajar.

Omar Mohammad At-Toumy As- Syaibany, 1979, Falsafah Pendidikan Islam, Jakarta:Bulan Bintang.

Paulo Freire, 2002, Politik Pendidikan: Kebudayaan, Kekuasaan, dan Pembebasan, terj. Agung Prihantoro dan 
Fuad Arif Fudiyartanto, Yogyakarta: Pustaka Pelajar \& READ.

, 2001, Pendidikan: Kegelisahan Sepanjang Zaman

(Pilihan Artikel Basis), Sindhunata (editor), Kanisius, sebagaimana di kutip dalam Resensi Amanat, Edisi 84/Februari 2001.

Sahal Mahfudh, Seminar Sehari SMU Islam Sudirman, Semarang: 8 Desember 1999.

Suyata dalam "Upaya Pembenahan Pendidikan Islam Lewat Penataan Kembali Pemikiran dan Penerapannya", dalam Yunahar Ilyas dan Muhammad Azhar (ed.) , 1999, Pendidikan dalam Perspektif al-Qur'an, Yogykarta: Lembaga Pengkajian dan Pengamalan Islam (LPPI) UMY.

Syaikh Taqiyuddin al-Nabhani, 1990, An-Nidzam Al-Iqtishadi fi al-Islam, Beirut: Dar al-Ummah.

Yusuf al-Qardhawi, 19980, Tarbiyah al-Islamiyah wa Madrasah Hasan al-Banna, diterjemahkan oleh Bustani A. Gani, Pendidikan Islam dan Madrasah Hasan alBanna, Jakarta: Bulan Bintang.

Thomas Kuhn, 2008, The Stucture of Scientific Revolutions; Peran Paradigma Dalam Revolusi Sains, (trj), Bandung: Rosdakarya.

--------, 1970, The Structure of Scientific Revolution, Chicago: The University of Chicago Press.

Toshihiko Izutsu, 1997, Relasi Tuhan dan Manusia, pendekatan Semantik terhadap al Qur'an, Yogyakarta : Tiara Wacana.

Zakiah Daradjat, et al, 2008, Ilmu Pendidikan Islam, Jakarta: Bumi Aksara, Cet.7.

Zuhairini, dkk., 1995, Sejarah Pendidikan Islam, Jakarta: Bumi Aksara. 